\title{
Value Proposition Testing Using Indirect Customer Observation Method for Personafic
}

\author{
Dhimas Satria Buana and Isti Raafaldini Mirzanti
}

\section{ABSTRACT}

\begin{abstract}
Many new businesses fail in the early years of their establishment because they do not have a value proposition that address customer problems and needs or wants. When it happens, the value offered to the customer becomes irrelevant, and does not create value for the customer at all. As a new business, Personafic, a men's skincare brand from Indonesia, became the object of the research on value proposition testing in this research. In this research, the hypothesis of the value proposition was validated using the indirect customer observation method using ads and landing pages, and assessed based on customer actions, not words. Tests carried out are interest validation, preference validation and willingness to pay validation of the customer. The results of the test show that the value proposition related to skincare product ingredients is the most attractive and most relevant value to customers.
\end{abstract}

Keywords: Indirect Customer Observation, Men's Skincare Brand, New Business, Value Proposition.

\section{INTRODUCTION}

\section{A. Background}

A business that is just starting out will be faced with a fairly high risk of failure. According to the Bureau of Labor Statistics report published on Fundera, 20\% of new businesses fail in the first year, and 50\% fail in the fifth year [1]. One of the causes of the failure of new businesses or start-ups is that they do not have an attractive value proposition to make potential customers making a purchase [2]. For this reason, business owners need to be more careful and smarter in planning and managing new businesses.

When starting a new business, one of the main focuses is building a product. For a new business, the product is a very critical point because one of the most influential factors in the success of a new business is product revenue [3]. This product revenue becomes a critical point because it becomes an indicator whether the product offered by a new business is accepted by the market or not. To increase product revenue, one thing that can be done is to increase the purchase intention of prospective customer [4], while purchase intention itself is obtained from the learning process that forms a perception. Perception of a product can be formed by communicating the attributes contained in the product. These attributes can be the characteristic of a business that distinguishes a business from other businesses, and can influence potential customers in making decisions regarding the purchase of these products [5].

To communicate these attributes to the customer, a message is needed which in this case is called the value proposition, so that the customer becomes more relevant to their problem, needs, or wants. When the value proposition is relevant, that is, when the value is expected to be able to
Submitted : June 16, 2021

Published : July 08, 2021

ISSN: 2507-1076

DOI: $10.24018 /$ ejbmr.2021.6.4.931

\section{Dhimas Satria Buana*}

Bandung Institute of Technology,

Bandung, West Java, Indonesia

(e-mail: dhimas_satria@sbm-itb.ac.id)

Isti Raafaldini Mirzanti

Bandung Institute of Technology,

Bandung, West Java, Indonesia

(e-mail: isti@ sbm-itb.ac.id)

*Corresponding Author solve their problems, or satisfy their needs or wants, then potential customers would have stronger considerations to make purchasing decisions. Likewise, if the value proposition is not relevant at all to their problems and needs or wants, then the customer would not consider making a purchase. To determine whether the value proposition that has been designed is relevant to the customer, it must be tested on the customer. In addition, this value proposition test must be carried out to reduce uncertainty about the new and improved value proposition before being adopted into the business model [6].

\section{B. Business Overview and Its Challenges}

Personafic is a skincare brand from Indonesia that provides facial skin care products specifically for men. The target market of Personafic is men aged 18-34 years, who have skin concerns, and have an interest in skincare products. Currently, Personafic has launched one product, namely facial wash, which is useful for cleaning the face from dust and dirt. In addition, this product can help to brighten the face, reduce acne, and reduce oily skin. Prospective customers do not need to worry about Personafic's products because it contains good quality and safe ingredients, namely charcoal, Centella asiatica, green caviar, galactosyl salicylate, tocopheryl, and Sakura extract. In addition to the good ingredients, the facial wash from Personafic also has good chemical properties, which is related to acidity or $\mathrm{pH}$. It has a $\mathrm{pH}$ of around 5.5-6 where this $\mathrm{pH}$ is more balanced with the $\mathrm{pH}$ of men's facial skin, which is 5.8 on average [7]. Products with a $\mathrm{pH}$ that is more balanced with the $\mathrm{pH}$ of the facial skin can reduce the risk of facial skin problems.

As a business that has just been started for less than one year, Personafic must immediately have a tested and 
validated value proposition. In testing and validating the value proposition, one of the main challenges is to run a value proposition test as quickly as possible with the lowest possible cost and obtain data from test results that can be measured quantitatively so that actionable insights are obtained. Finally, the validated value proposition is expected successfully to be adopted into the business model and can help Personafic in increasing products revenue at the beginning of its establishment.

\section{Research Objective}

As explained earlier that before being adopted into the business model, the value proposition must be validated first to reduce uncertainty about the value proposition that will be accepted or not by the customer. Thus, the objective of this research is to validate the value proposition of Personafic so that the value becomes more relevant and accepted by potential customers.

\section{LITERATURE REVIEW}

\section{A. Value Proposition}

Recently, the term 'value proposition' is very commonly used in business and marketing. A value proposition is a statement about an explicit promise made by the company and offered to its customers that creates a differential within the customer's decision process so that it makes customers choose the company's offer compared to competitors [8]. Value proposition is also known as a statement that describes the core and essence of a business strategy and a description that distinguishes a business from other businesses [9].

\section{B. Value Proposition Testing}

Although the term value proposition has been widely used, research and discussion on best practice on how to test and evaluate a value proposition has not been done much. One of the researchers who discusses the best practice and comprehensive value proposition creation and evaluation is Osterwalder in his book Value Proposition Design. The book describes in detail the methods used to design the value proposition, starting with designing the value proposition canvas which consists of a customer profile (customer jobs, pains, and gains) and a value map (products and services, pain relievers, and gain creators), and methods for testing the value proposition [6]. Osterwalder explained in detail with a customer centric approach, namely that all assumptions made must be immediately validated to the customer before proceeding to the next stage, such as business model evaluation, etc.

\section{MethodOLOGY}

\section{A. Research Framework}

This research used the value proposition testing framework by Osterwalder, which can be seen in Fig 1. Based on the framework, the stages that must be evaluated to validate a hypothesis are interest, preference, and willingness to pay validation, so that if the three stages of testing get positive results, then the value proposition being tested is validated.

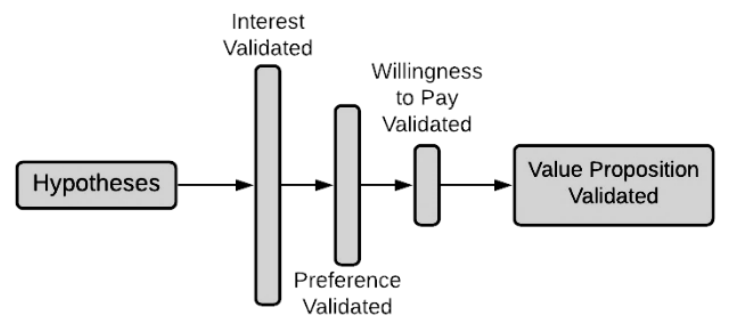

Fig. 1. Value proposition testing framework [6].

\section{B. Value Proposition Hypotheses}

In this research, the author proposes three value proposition hypotheses to be tested. The hypothesis of the value proposition can be seen in Table I.

TABLE I: VALUE PROPOSITION HYPOTHESES

\begin{tabular}{|c|c|c|c|}
\hline No & Hypothesis & Value Proposition & $\begin{array}{c}\text { Value } \\
\text { Proposition } \\
\text { Focused }\end{array}$ \\
\hline 1 & $\begin{array}{l}\text { People need a skincare } \\
\text { product with low } \mathrm{pH}\end{array}$ & $\begin{array}{l}\text { Men's facial wash } \\
\text { with low pH }\end{array}$ & $\begin{array}{l}\text { Unique } \\
\text { Properties }\end{array}$ \\
\hline 2 & $\begin{array}{l}\text { People want a product } \\
\text { that made from certain } \\
\text { active ingredients }\end{array}$ & $\begin{array}{l}\text { Made with good } \\
\text { quality active } \\
\text { ingredients }\end{array}$ & $\begin{array}{l}\text { Product } \\
\text { Ingredients }\end{array}$ \\
\hline 3 & $\begin{array}{l}\text { People want to } \\
\text { brighten the skin, } \\
\text { reduce oily skin, and } \\
\text { get rid of acne }\end{array}$ & $\begin{array}{l}\text { Brighten the skin, } \\
\text { reduce oily skin, } \\
\text { and get rid of acne }\end{array}$ & $\begin{array}{l}\text { Product } \\
\text { Benefit }\end{array}$ \\
\hline
\end{tabular}

The following is a brief explanation of the value proposition hypothesis:

1. This hypothesis emphasizes the product characteristics, namely low $\mathrm{pH}$. Products with this property is expected to address customer problems that they are worried about their skin will be irritated, dry and breakout after using facial wash products.

2. The focus of this hypothesis is the active ingredient in facial wash products, so that value is communicated by linking the benefits of the product obtained from the product with the content of certain active ingredients. This value is expected to meet their needs that they need products with good quality and safe active ingredients.

3. Unlike the previous two hypotheses, the third value proposition hypothesis only focuses on the benefits that customers get when using products from Personafic, without conveying the chemical or physical properties of the product.

\section{Research Method}

The method used in this research is indirect observation of customers. Indirect observation is a recent concept that can be used to study behavior using various data sources, one of which is advertisement or ads [10]. Indirect observation tends to be used when data cannot be collected by direct means [11], for example, to find out someone's interest, instead of asking the person directly, tracking actions on digital behavior such as how someone behaves with display ads are carried out. In line with that, 
Osterwalder explained that indirect observation of customer is used to verify that the customer is interested in a product and to verify whether a customer means what they say, by analyzing their behavior using ads, link tracking, landing pages, and split testing [6].

This research aims to know that the value proposition of Personafic is attractive and relevant to customers, with real and genuine actions, not with words. Interest, preference, and willingness to pay of customers will be identified by analyzing customer behavior towards ads and landing pages. First, product's ads that convey several hypotheses from the value proposition are displayed to a number of audiences. After that, validation, and assessment of the hypotheses of the value proposition occurs when the audience performs certain actions, namely clicks on the ads and visits the landing page, clicks on the call-to-action (CTA) button on the landing page to make a purchase, and finally complete the payment. This method is powerful for generating quantitative data from ads and landing page tracking actions, so this data can be used as metrics that can be measured and compared.

\section{FINDING AND ANALYSIS}

\section{A. Interest Validation}

Interest validation aims to validate the idea of the value proposition offered by Personafic whether it is interesting or not for the audience. Audience who are genuinely interested in the idea will take an action in the form of clicking ads then directing to the landing page to find out more about the idea that Personafic are proposing. Table II shows the results of the interest validation test.

TABLE II: INTEREST VALIDATION TEST RESULT

\begin{tabular}{lccc}
\hline \multicolumn{1}{c}{ Metrics } & VP 1 & VP 2 & VP 3 \\
\hline Video plays up to 50\% & 4773 & 3998 & 4303 \\
Landing page view & 192 & 175 & 167 \\
Landing page view rate* & $4,02 \%$ & $4,38 \%$ & $3,88 \%$ \\
\hline \hline
\end{tabular}

Note: VP represent value proposition.

Video views of up to $50 \%$ is a metric we use to show that an audience has seen and is expected to understand the message conveyed in a video ad. Of the audience who saw the message, some of them were interested in the value conveyed in the ad, namely those who took action in the form of clicking on the ad and then visiting the landing page where the value proposition was explained in more detail. We classify those audience as an audience whose interests are validated. Based on Table II above, value proposition 2 is the most attractive and relevant to the customer interest, followed by value proposition 1 and 3 .

\section{B. Preference Validation}

After visiting the landing page and seeing a more detailed explanation of the ideas in the value proposition, visitors are faced with the choice to take action in the form of clicking the CTA-button to make a purchase or do nothing at all. Preference is validated when the visitor performs the action. The results of the preference validation test can be seen in Table III.
TABLE III: PREFERENCE VALIDATION TEST RESULT

\begin{tabular}{lccc}
\hline \hline \multicolumn{1}{c}{ Metrics } & VP 1 & VP 2 & VP 3 \\
\hline Landing page view & 192 & 175 & 167 \\
Click CTA-button & 49 & 55 & 30 \\
Click CTA-button rate* & $25,52 \%$ & $31,43 \%$ & $17,96 \%$ \\
\hline \hline
\end{tabular}

Based on TABLE III above, the highest preference occurs when the product is offered with a value proposition of 2 . The three results of preference testing produce quite significant differences, especially between the most preferred which is value proposition 2 and least preferred which is value proposition 3 , the difference in results is up to $13 \%$.

\section{Willingness to Pay Validation}

When performing an action in the form of clicking the CTA button, the audience is also faced with a choice, namely, to complete the payment transaction or not to complete the payment transaction. When the audience completes the payment transaction, then the audience is validated at the stage of willingness to pay. Table IV below shows the results of the willingness to pay validation test.

TABLE IV: WILLINGNESS TO PAY VALIDATION TEST RESULT

\begin{tabular}{lccc}
\hline \hline \multicolumn{1}{c}{ Metrics } & VP 1 & VP 2 & VP 3 \\
\hline Click CTA-button & 49 & 55 & 30 \\
Purchase & 9 & 10 & 4 \\
Purchase rate* & $18,37 \%$ & $18,18 \%$ & $13,33 \%$ \\
\hline \hline
\end{tabular}

Based on the table above, value proposition 1 produces the best willingness to pay, followed by value proposition 2 where the difference in test results is not too significant. Value proposition 3 produces the lowest willingness to pay compared to other value propositions.

From the test results above, Table V shows a summary of the test results of interest, preference, and willingness to pay validation. It can be seen that the interest validation test, which is indicated by landing page view rates, produces the best results for value proposition 2. Likewise with preference validation, which is indicated by the CTA-button rate click metrics, it also shows that value proposition 2 is the most preferred value according to the audience. Testing of willingness to pay shows value propositions 1 and 2 produce better values than value proposition 3 .

TABLE V: RESULT TEST SUMMARY

\begin{tabular}{lccc}
\hline \hline \multicolumn{1}{c}{ Metrics } & VP 1 & VP 2 & VP 3 \\
\hline Landing page view rate $^{\mathrm{C}}$ & $4,02 \%$ & $4,38 \%$ & $3,88 \%$ \\
Click CTA-button rate & $25,52 \%$ & $31,43 \%$ & $17,96 \%$ \\
Purchase rate & $18,37 \%$ & $18,18 \%$ & $13,33 \%$ \\
\hline \hline
\end{tabular}

\section{CONCLUSION}

This research aims to test the three hypotheses of the Personafic value proposition. We tested the value proposition using indirect observation of customers to assess the hypothesis of the value proposition. By using this method, the results obtained are more genuine and real, because validation is carried out using actions, not just words. 
The following are the conclusions this research:

1. Value proposition 2, the value related to the active ingredients contained in the product, is the most attractive and most preferred value. This value is the most relevant value to the customer compared to other value propositions.

2. From the willingness to pay test, it results value proposition 1 , which is related to the $\mathrm{pH}$ product, is the value proposition that generates the highest willingness to pay, followed by value proposition 2 , with very small and insignificant differences.

3. Value proposition 3, regarding the benefits of products that can brighten the skin, reduce oily skin, and get rid of acne, is the least attractive value, least preferred, and results in the lowest willingness to pay compared to the other value propositions.

Based on the test results, Personafic must create an effective value proposition delivery strategy and emphasize the message of the active ingredients contained in the product. This is important to do in order to reduce irrelevant value delivery activities and have no impact on revenue, so that in the early years of business establishment, Personafic will minimize the risk of business failure and survive to compete with competitors.

\section{REFERENCE}

[1] G. McIntyre, "What Percentage of Small Businesses Fail?," 2020. https://www.fundera.com/blog/what-percentage-of-small-businessesfail? (accessed May 24, 2021).

[2] D. Skok, "5 Reasons Startups Fail - For Entrepreneurs." https://www.forentrepreneurs.com/why-startups-fail// (accessed May 24, 2021).

[3] A. M. Kazerouni, S. Achiche, O. Hisarciklilar, and V. Thomson, "Influence of the time perspective on new product development success indicators," ICED 11 - 18th International Conference on Engineering Design - Impacting Society Through Engineering Design, vol. 3, pp. 40-51, 2011.

[4] L. Y. Chen, "The Quality of Mobile Shopping System And Its Impact On Purchase Intention And Performance," International Journal of Managing Information Technology, vol. 5, 2013.

[5] G. Teja, K. Putra, and R. Harijanto, "The Impact of Customer Value Proposition Towards Purchase Intention of Chesa Cup," iBuss Management., vol. 3, no. 2, pp. 241-251, 2015.

[6] A. Osterwalder, Y. Pigneur, G. Bernarda, and A. Smith, Value Proposition Design. John Wiley \& Sons, 2014.

[7] C. Ehlers, U. I. Ivens, M. L. Møller, T. Senderovitz, and J. Serup, "Females have lower skin surface $\mathrm{pH}$ than men: A study on the influence of gender, forearm site variation, right/left difference and time of the day on the skin surface pH," Skin Research and Technology, vol. 7, no. 2, pp. 90-94, 2001, doi: 10.1034/j.16000846.2001.70206.x.

[8] A. Hassan, "The Value Proposition Concept in Marketing: How Customers Perceive the Value Delivered by Firms - A Study of Customer Perspectives on Supermarkets in Southampton in the United Kingdom," International Journal of Marketing Studies, vol. 4, no. June 2012, 2012, doi: 10.5539/ijms.v4n3p68.

[9] P. Frow, J. R. McColl-Kennedy, T. Hilton, A. Davidson, A. Payne, and D. Brozovic, "Value propositions: A Service Ecosystems Perspective," Marketing Theory, vol. 14, no. 3, pp. 327-351, 2014, doi: $10.1177 / 1470593114534346$.

[10] M. T. Anguera, M. Portell, S. Chacón-Moscoso, and S. SanduveteChaves, "Indirect observation in everyday contexts: Concepts and methodological guidelines within a mixed methods framework," Frontiers in Psychology, vol. 9, no. JAN, p. 13, Jan. 2018, doi: 10.3389/fpsyg.2018.00013.

[11] A. Parasuraman, Marketing Research, 2nd ed. Addison-Wesley, 1991.

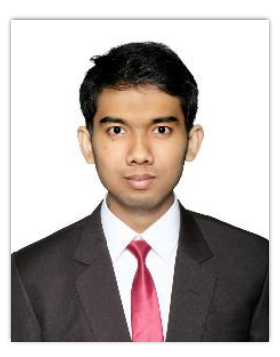

Dhimas Satria Buana was born on September $7^{\text {th }} 1997$ in Sragen, Indonesia. Graduated from Metallurgical Engineering at Bandung Institute of Technology in 2019. He pursued his master degree in Master of Business Administration at the same university, focusing in cultural and creative entrepreneurship program. He is very interested in entrepreneurship, especially those related to the grooming and skincare industry.

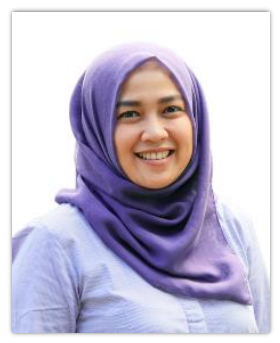

Isti Raafaldini Mirzanti was born on October $1^{\text {st }}$ 1976 in Bandung, Indonesia. She completed her doctoral program in School of Business and Management, Bandung Institute of Technology, majoring entrepreneurship policy in 2016. Her expertise in research is entrepreneurship policy, start-up valuation, creative economy, social entrepreneurship, and technology management. Currently, Dr. Mirzanti works as lecturer and researcher in Entrepreneurship and Technology Management Interest Group, School of Business and Management, Bandung Institute of Technology. 